\title{
Neurofilaments Help Maintain Normal Morphologies and Support Elongation of Neurites in Xenopus laevis Cultured Embryonic Spinal Cord Neurons
}

\author{
Weichun Lin and Ben G. Szaro \\ Department of Biological Sciences and the Neurobiology Research Center, University at Albany, State University of \\ New York, Albany, New York 12222
}

\begin{abstract}
Neurofilament number and subunit composition, which are highly regulated during development, have been proposed to help regulate axonal diameter and stability. From experiments on dissociated cell cultures of Xenopus laevis embryonic spinal cord, we have obtained direct evidence that neurofilaments help maintain the structural integrity of newly developing axons. An anti-neurofilament monoclonal antibody specific for Xenopus NF-M and the cell lineage tracer, lysinated FITC-dextran, were coinjected into a single blastomere of 2-cell stage embryos. Within neurons descended from the injected blastomere, this antibody specifically confined neurofilaments to the cell body for the first two days of culture, as assayed by immunocytochemical staining with antiserum against the low molecular weight neurofilament protein XNIF. Although whole IgGs and Fab fragments both affected neurofilament distribution, the whole IgGs were more effective. For the first $9 \mathrm{hr}$ of culture, neurltes contalning antI-NF-M developed normally. By $21 \mathrm{hr}$, they were shorter than those of sibling control neurons within the same dish, and many became morphologically abnormal. Defects included large variations in diameter, poorly defined separations between the growth cone and neurite, and more collateral branching. Despite these abnormal features, neurons containing antiNF-M had normal distributions of $\alpha$-tubulin immunoreactivity and phalloidin-stained F-actin. These latter observations argued that defects resulted from the absence of neurofilaments rather than from interference of the movement of other structural materials essential for axonal growth. These results support the hypothesis that neurons use neurofilaments to help maintain the characteristic shapes of axons against the increasing structural demands placed upon the elongating process.
\end{abstract}

\footnotetext{
Received July 6, 1995; revised Aug. 18, 1995; accepted Aug. 28, 1995.

We thank Dr. Lawrence Charnas for the anti-XNIF antiserum. Dr. Jeff Travis for the anti- $\alpha$ tubulin antibody, and Dr. John Schmidt for the phalloidin. We thank Dr. Michael Klymkowsky for his advice concerning the E7 anti- $\beta$-tubulin monoclonal antibody and the Developmental Studies Hybridoma Bank maintained by the Department of Pharmacology and Molecular Sciences at the Johns Hopkins University School of Medicine and the Department of Biology at the University of Iowa, Iowa City, IA (under Contract NOl-HD-2-3144 from the NICHD) for providing the ascites fluid for it. We also thank Rusty Gonser for his help in maintaining the breeding stock used in these experiments. Drs. John Schmidt and Suzannah Tieman provided useful, critical comments on the manuscript. This work was supported by a grant (R29 NS30682) from the NINDS, National Institutes of Health.

Correspondence should be addressed to Ben G. Szaro, Biology Department University at Albany, SUNY, 1400 Washington Avenue, Albany, NY 12222.
}

Copyright (C) 1995 Society for Neuroscience $0270-6474 / 95 / 158331-14 \$ 05.00 / 0$
[Key words: neurofilament, cytoskeleton, neurite outgrowth, axonal development, spinal cord development, Xenopus laevis]

The axonal cytoskeleton comprises microfilaments, microtubules and neurofilaments. During axonal development, microfilaments are essential for growth cone motility and neurite initiation (for a recent example, see Smith, 1994), whereas microtubules are needed for neuritic extension (Mitchison and Kirschner, 1988) and for transporting essential materials into the growing axon (Allen et al., 1985; Schnapp et al., 1985). Neurofilament function has been more extensively considered in adult axons than in developing ones, because neurofilaments emerge later than microfilaments and microtubules. In mature peripheral myelinated axons, for example, neurofilaments clearly enhance axonal caliber (Friede and Samorajski, 1970; Hoffman et al., 1987; Cole et al., 1994; Eyer and Peterson, 1994). However, neurofilaments probably serve other functions too, since they are also found in axons whose diameter is less dependent on neurofilament content (Parhad et al., 1987; Szaro et al., 1990). The physical chemical properties of neurofilaments, like those of other intermediate filaments, have led investigators to suggest that neurofilaments strengthen and consolidate the axonal cytoskeleton (Leterrier and Eyer, 1987; Eyer et al., 1989). The possibility that neurofilaments are important during axonal development is raised by studies that document the emergence and changing molecular compositions of neurofilaments in actively growing axons of embryos (Shaw and Weber, 1982; Pachter and Liem, 1984; Dahl and Bignami, 1986; Carden et al., 1987; Szaro et al., 1989; Fliegner et al., 1994) and regenerating nerves (Oblinger et al., 1989b; Tetzlaff and Bisby, 1989; Troy et al., 1990; Glasgow et al., 1992; Landmesser and Swain, 1992; Liuzzi and Tedeschi, 1992; Zhao and Szaro, 1994). One possibility is that neurofilaments of immature axons, which differ markedly in molecular composition from those of mature axons, only partially consolidate the cytoskeleton, thereby contributing to axonal stability while permitting growth to continue (Schwartz et al., 1990).

One of the few studies to provide direct experimental evidence in support of this idea is an antibody injection experiment conducted on intact Xenopus laevis embryos (Szaro et al., 1991). In this study, several monoclonal antibodies to nonphosphorylated epitopes of the middle molecular weight neurofilament protein (NF-M) were injected into a single blastomere of 2-cell stage embryos. These antibodies persisted for several days and produced accumulations of neurofilaments within the cell bodies of neurons descended from the injected blastomere. The injected 
anti-NF-M antibodies also reduced the extent of peripheral axonal outgrowth achieved by stage 39/40. Although these experiments were suggestive, it was difficult to draw firm conclusions from these results since it was impossible to distinguish individual axons within the nerves and tracts. Conducting similar experiments on newly developing neurons isolated in dissociated cell culture would permit the observation of effects in greater detail.

During the first $2 \mathrm{~d}$ of neuronal development, neurite outgrowth can be followed in cultures of dissociated spinal cord neurons made from the neural tubes of Xenopus laevis embryos (Tabti and Poo, 1991). The expression of the neurofilament proteins NF-M, XNIF, and NF-L, and the subsequent phosphorylation of NF-M follow the same timecourse in such cultures as in the intact embryo (Lin and Szaro, 1994). We now present details on the development of neurites in such cultures made from embryos that had a single blastomere at the 2-cell stage injected with an antibody against NF-M. This antibody, either as whole IgG molecules or as Fab fragments, specifically eliminated neurofilament protein immunoreactivity from developing neurites without altering the distributions of $\alpha$-tubulin or F-actin. During the first $9 \mathrm{hr}$ of culture, all neurites were normal. However by $21 \mathrm{hr}$, neurites lacking neurofilament immunoreactivity were shorter on average than those of normal neurons from the same embryo developing in the same culture. In addition, many of these neurites were morphologically abnormal. These results are the first clear demonstration of what happens to developing axons when they are deprived of their neurofilaments.

\section{Materials and Methods}

\section{Embryonic blastomere injections}

Fertilized eggs were continually collected for several hours from normal spawnings of periodic albino Xenopus laevis frogs (Hoperskaya, 1975; Tompkins, 1977) induced by intraperitoneal injection of human chorionic gonadotropin (Sigma, St. Louis, MO) the night before (Gurdon, 1967). Embryonic jelly coats were removed by immersing eggs in a dejellying solution $(10 \mathrm{~mm}$ dithiothreitol $/ 50 \mathrm{~mm}$ Tris, $\mathrm{pH} 8$ in dechlorinated tap water) for $2-3 \mathrm{~min}$ and then rescuing them with extensive washes in dechlorinated tap water. Viable embryos at the 2-cell stage were then selected for microinjection. To eliminate hydrostatic pressure created by the vitelline membrane, embryos were placed in a solution of 5\% Ficoll (Sigma, St. Louis, MO) in Hepes buffered Steinberg's solution [HBS: $58.2 \mathrm{~mm} \mathrm{NaCl}, 0.67 \mathrm{~mm} \mathrm{KCl}, 0.34 \mathrm{~mm} \mathrm{Ca}\left(\mathrm{NO}_{3}\right)_{2}, 0.83$ $\mathrm{mm} \mathrm{MgSO}_{4}, 5$ mм Hepes, $\mathrm{pH}$ 7.6].

The procedure for microinjection was identical to that used previously (Szaro et al., 1991), except that micropipettes were mechanically beveled to a tip diameter of $8-12 \mu \mathrm{m}$, and the injection pressure was lowered to $15-20$ p.s.i. These changes dramatically increased survival rates for the injected embryos and enabled us to inject higher doses of antibody than before. Injection volumes were controlled by an electronically gated apparatus (Picospritzer II, Fairfield, NJ) that was pneumatically driven by pressure from a tank of dry nitrogen. Each pipette was calibrated through an ocular micrometer by measuring the size of a droplet ejected into mineral oil. Embryos were injected near the animal pole of a single blastomere at the 2-cell stage. After several hours, but prior to gastrulation, injected embryos were passed through a graded series of HBS solutions into $20 \%$ sterile HBS with no Ficoll. In all, embryos were collected from 11 separate spawnings.

\section{Solutions for microinjection}

The mouse monoclonal antibody XC10C6, which is directed against Xenopus NF-M (Szaro and Gainer, 1988; Szaro et al., 1989), was used to perturb neurofilaments. This antibody was one of several used in the previous study to perturb neurofilaments in intact embryos (Szaro et al., 1991), and our whole IgG solution came from the same stock. It was prepared by purifying whole IgGs from mouse ascites fluid over a protein A column (Affi-gel Protein A, MAPS II Kit; Bio-Rad, Richmond, $\mathrm{CA})$ according to the manufacturer's instructions.

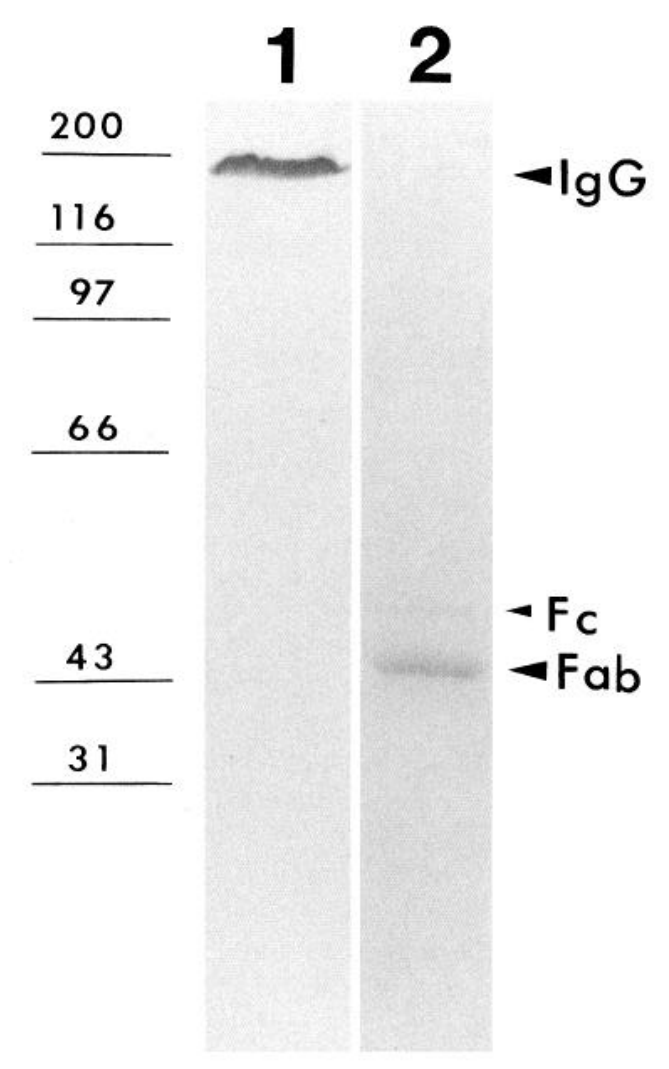

Figure 1. SDS-polyacrylamide gel electrophoresis of anti-NF-M antibody solutions. Lane 1 shows $18 \mu \mathrm{g}$ of purified XC10C6 whole IgG run under nonreducing conditions. Lane 2 shows $7 \mu \mathrm{g}$ of total protein containing Fab fragments under nonreducing conditions. Although in addition to the Fab frament some residual Fc is visible, the solution is

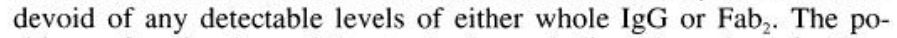
sitions of molecular weight standards are indicated on the left. They are: myosin, $200 \mathrm{kDa}$; $\beta$-galactosidase, $116 \mathrm{kDa}$; phosphorylase $\mathrm{B}, 97$ $\mathrm{kDa}$; bovine serum albumin, $66 \mathrm{kDa}$; ovalbumin, $43 \mathrm{kDa}$; and carbonic anhydrase, $31 \mathrm{kDa}$.

Fab fragments of XC10C6 were prepared from purified IgG, which was mixed with an equal amount of papain immobilized to agarose beads (Calbiochem, La Jolla, CA) in a final volume of $1.8 \mathrm{ml}$ and digested at $37^{\circ} \mathrm{C}$ for $40 \mathrm{hr}$ with continuous agitation. [Conditions for digestion were previously determined through analysis of partially digested aliquots by SDS-polyacrylamide gel electrophoresis (SDSPAGE)]. Papain-agarose was removed by centrifugation and the supernatant was passed through a protein A agarose column (Calbiochem) to remove $\mathrm{Fc}$ fragments. The column flow-through, containing Fabs, was washed by five repeated cycles of concentration through a CentriPor centrifuge concentrator column (Spectrum) and subsequent dilution with $0.1 \times$ HBS. This concentrated solution was then lyophilized and reconstituted in Milli-Q filtered water. Figure 1 shows aliquots of both the whole IgG antibody solution and the Fab fragment solution separated by $10 \%$ SDS-PAGE under non-reducing conditions. As seen in lane 2, the solution of Fab fragments was free of both whole IgG and $\mathrm{Fab}_{2}$, but did contain some residual $\mathrm{Fc}$ that had failed to bind to the protein A column. The small residual amount of Fc that remained was unlikely to have been responsible for the antibody effects, since none of the control IgG antibodies used affected neuronal development.

Three substances were injected as controls. The first was the monoclonal antibody E7, which was obtained as ascites fluid from the Developmental Studies Hybridoma Bank (Iowa City, IA). Although this antibody binds to Xenopus laevis $\beta$-tubulin (Chu and Klymkowsky, 1989; Dent et al., 1989; Klymkowsky et al., 1987), it fails to perturb microtubule polymerization, cell division, or normal development when it is injected into embryonic blastomeres (Klymkowsky et al., 1987; Chu and Klymkowsky, 1989; Dent et al., 1989). E7 ascites fluid was purified the same way as was XC10C6. The second control antibody was a commercially available, purified mouse monoclonal antibody di- 
rected against $F$. coli $\beta$-galactosidase (Promega, Madison, WI). All injected antibodies were mouse monoclonal IgGs. Bovine serum albumin (BSA, grade V; Sigma, St. Louis, MO) was used as an additional control for the viability of injected embryos (Szaro et al., 1991).

Prior to final dilution, the concentrations of purified antibodies were determined by absorbance at $280 \mathrm{~nm}\left(\mathrm{~A}_{280}\right.$ of 1.0 is $\left.740 \mu \mathrm{g} / \mathrm{ml}\right)$. Before injection, each solution was mixed with an equal volume of $1.5 \%$ lysinatedfluorescein-isothiocyanate-dextran (lys-FITC-DX, Molecular Probes, Eugene, $\mathrm{OR}$ ), which allowed us to identify in culture the cells descended from the injected blastomere. In the first set of experiments, 25 cultures were made from embryos injected with lys-FITC-DX alone, and stained for neurofilaments with anti-XNIF. In these cultures, lys-FITC-DX positive neurons were normal in every aspect. The final concentrations and numbers of cultures analyzed for each injected protein were: XC10C6, whole $\operatorname{IgG}, 4.5$ ng/nl, 79 cultures; XC10C6, Fab fragments, either $3.5 \mathrm{ng} / \mathrm{nl}$ or $7 \mathrm{ng} / \mathrm{nl}$, total of 28 cultures; E7, $3.5 \mathrm{ng} / \mathrm{nl}, 19$ cultures; anti- $\beta$-galactosidase, $4.5 \mathrm{ng} /$ nl, 27 cultures; and BSA, $5 \mathrm{ng} / \mathrm{nl}, 24$ cultures. For whole IgGs and BSA the volumes of the injections were generally $28-12 \mathrm{nl}$. These were adjusted so that each embryo nominally received $100-150 \mathrm{ng}$ of total protein. The amount of Fab fragments injected was either $100 \mathrm{ng}$ or 200 ng per embryo, as described in the Results.

\section{Preparation of dissociated neural tube cultures}

After injection, embryos were raised to stage 22 (Nieuwkoop and Faber, 1956) and examined briefly under FITC-fluorescence. Healthy looking, unilaterally labeled embryos were selected for dissociated neural tube cultures, and placed into sterile-filtered HBS. More detailed protocols for preparing such cultures can be found elsewhere (Anderson et al., 1977; Cohen et al., 1987; Tabti and Poo, 1991). Briefly, the vitelline membrane was manually removed and a dorsal portion of the embryo consisting of the developing spinal cord and adjacent epithelium, somites and notochord was dissected free. These tissues were then incubated in a collagenase solution $(0.5 \mathrm{mg} / \mathrm{ml}$, type IV, Sigma, St. Louis, $\mathrm{MO}$ ) for $30-50 \mathrm{~min}$ and transfered to HBS. The neural tube was then dissected away from other tissues and incubated in a calcium-magnesium free HBS solution $(58.2 \mathrm{~mm} \mathrm{NaCl}, 0.67 \mathrm{~mm} \mathrm{KCl}, 5 \mathrm{~mm}$ Hepes, $\mathrm{pH} 7.4,0.5 \mathrm{~mm}$ EDTA) for an additional $30-60 \mathrm{~min}$. The neural tube was dissociated gently by trituration through a micropipette, and resultant cells from a single neural tube were placed into $35 \mathrm{~mm}$ culture dishes containing medium [60\% Leibowitz's L-15 with glutamine (GIBCO/BRL, Gaithersburg, MD), 39\% HBS, $1 \%$ CPSR-1 serum substitute (Sigma, St. Louis, MO)]. Cells were plated directly onto the bottoms of the dishes, which were made of $\Delta$ polystyrene plastic (Nunclon, Naperville, IL). This plastic provided a uniform, commercially prepared substrate that minimized dish to dish variations in rates of normal neuritic outgrowth (Lin and Szaro, 1994). Previously, we demonstrated that the neurofilament proteins XNIF, NF-M, NF-L, and phosphorylated epitopes of NF $M$ emerge in cultured neurons following the same time course as in the intact embryo (Lin and Szaro, 1994).

\section{Histochemistry}

Localization of injected antibodies. The persistence and distribution of the injected antibodies in cultured neurons were examined immunocytochemically with the appropriate secondary antibody. In the case of injected whole IgG solutions, a biotinylated anti-mouse IgG (Vector Laboratories, Burlingame, CA), diluted 1:800, was used. In the case of injected $\mathrm{Fab}$ fragments, we used a biotinylated anti-mouse-Fab specific antibody diluted 1:1000 (Sigma, St. Louis, MO). Cultures were fixed with $3.7 \%$ formaldehyde plus $0.25 \%$ glutaraldehyde in $0.1 \mathrm{M}$ sodium phosphate buffer ( $\mathrm{pH} \mathrm{7.4)}$ ) for 15-30 min. The fixed cultures were then extracted with $0.5 \%$ triton $\mathrm{X}-100$ in $0.1 \mathrm{~m}$ sodium phosphate, $\mathrm{pH}$ 7.4. Next, the cultures were incubated sequentially in a protein solution (5\% bovine serum albumin, $3 \%$ normal serum in tris buffered saline), an avidin solution and then a biotin solution (AB-blocking kit, Vector Laboratories, Burlingame, $\mathrm{CA}$ ). The cultures were then incubated with the appropriate biotinylated antibody followed by rhodamine-avidin $\mathrm{D}$ diluted 1:1000 (Vector Laboratory, Burlingame, CA). After several washes in tris buffered saline, the cultures were covered with a glass coverslip sealed with aqueous mounting medium (Permafluor, Shandon Lipshaw, Pittsburgh, PA). For these experiments, 25, 8, 3, and 5 cultures were prepared from embryos injected with anti-NF-M (whole IgG), anti-NF-M (Fab), anti- $\beta$ tubulin, and anti- $\beta$ galactosidase, respectively.

Immunocytochemical staining for $\alpha$-tubulin. The procedure was simlar to that described above, except that the primary antibody was a sheep antiserum against bovine brain $\alpha$-tubulin (Southern Biotechnology Assoc., Birmingham, AL), diluted 1:100. For these experiments, 8, 5 , and 3 cultures were prepared from embryos injected with anti-NF-M (whole $\operatorname{IgG}$ ), anti- $\beta$ tubulin and BS $\Lambda$, respectively.

Immunocytochemical localization of neurofilaments. The distribution of neurofilaments was determined by immunostaining with a rabbit antiserum (LC2) directed against the Xenopus neuronal intermediate filament protein (XNIF; Charnas et al., 1992), diluted 1:500. Use of this antiserum to localize XNIF in cells injected with FITC-DX required moditications in the fixation protocols, since the epitope of the XNIF antiserum is sensitive to aldehydes, which were necessary for proper fixation of the lysinated dextran. Cultures were first fixed by dropwise addition of methanol (Lin and Szaro, 1994), and then briefly postfixed for $20 \mathrm{~min}$ with an aldehyde containing fixative $3.7 \%$ formaldehyde, $0.25 \%$ glutaraldehyde, $0.1 \mathrm{~m}$ sodium phosphate, $\mathrm{pH} 7.4$ ) further diluted $1: 25$ in $0.1 \mathrm{M}$ sodium phosphate. This method retained lys-FITC-DX without damaging neurofilament epitopes. For these experiments, 27, $11,5,7$, and 12 cultures were made from embryos injected with anti NF-M (whole IgG), anti-NF-M (Fab), anti- $\beta$ tubulin, anti- $\beta$ galactosidase, and BSA, respectively.

Localization of $F$-actin by phalloidin. Cultures were fixed in aldehyde fixative and then extracted with Triton X-100 as described above. Cultures were washed several times with $0.1 \mathrm{M}$ sodium phosphate, $\mathrm{pH} 7.4$, and then incubated for $40 \mathrm{~min}$ in $5 \mathrm{U} / \mathrm{ml}$ rhodamine-phalloidin in phosphate buffer (Molecular Probes, Eugene, OR). Afterward, cultures were washed with $0.1 \mathrm{M}$ sodium phosphate, $\mathrm{pH} 7.4$, and placed under coverglasses as described for the other histochemical protocols. For these experiments, 7, 3, and 3 cultures were made from embryos injected with anti-NF-M (whole IgG), anti- $\beta$ galactosidase and BSA, respectively.

\section{Analysis of neuritic lengths}

Cultures at either 9 or $21 \mathrm{hr}$ after plating were fixed in aldehyde fixative and then preliminarily examined under fluorescence to distinguish neurons derived from the injected blastomere (lys-FITC-DX-positive) from their contralateral sibling neurons (lys-FITC-DX-negative). Under phase contrast illumination, camera lucida drawings were made of the cell body and principal neuritic process of every unipolar neuron that was sufficiently isolated from other neurons to avoid confusion. These tracings were then entered into a microcomputer via a digitizing tablet, and the lengths of the primary neurites were measured and stored (Szaro and Tompkins, 1987). If the primary neurite branched into two separate processes of approximately equal diameter, the lengths of both processes were measured and added to the total neuritic length for that cell. However, the very fine collateral processes and protrusions along the primary neurite were not included, since these extensions appeared qualitatively different from the main neuritic process. The lengths of all neurites in each group, either lys-FITC-DX-positive or -negative, were then averaged for a single culture dish. For each of the injected substances, these means were then averaged over six separate cultures, and the data were tabulated (Table 1). The significance of the difference between neuritic lengths of lys-FITC-DX-positive and -negative neurons was determined for each substance by taking the difference of the mean neuritic lengths between the lys-FITC-DX-positive and -negative neurons for each dish, and then computing a two-tailed paired $t$ test for the six cultures in each group (Sachs, 1984).

\section{Results}

\section{Injected antibodies persist for $2 d$ in cultured neurons}

During Xenopus laevis development, the first cleavage plane demarcates the future anatomical midline of the animal (Hirose and Jacobson, 1979). Thus, injection of a cell lineage tracer into one blastomere at the 2-cell stage labels the neural tube on the side of the injection. Unlabelled neurons cultured from the neural tube of an injected embryo therefore act as the ideal internal control for effects of injected substances on labelled neurons, provided that the injection itself is harmless. In our experiments, lys-FITC-DX was added to antibody solutions to mark all of the subsequent cultured neurons that were descended from the injected blastomere. By counting the number of labeled and unlabeled neurons in 24 cultures during the first day after plating, we verified that injection of a blastomere with mixtures of lys- 
I'able 1. Effects of injected substances on average neuritic length $(\mu \mathrm{m})^{a}$

\begin{tabular}{|c|c|c|c|c|c|}
\hline & \multicolumn{2}{|c|}{ Injected Cells } & \multicolumn{2}{|c|}{ Uninjected Cells } & \multirow[b]{2}{*}{$P^{c}$} \\
\hline & $\begin{array}{l}\text { Cell } \\
\text { number }\end{array}$ & Length & $\begin{array}{l}\text { Cell } \\
\text { number }\end{array}$ & Length & \\
\hline \multicolumn{6}{|l|}{ A. $21 \mathrm{hr}$ after plating } \\
\hline \multicolumn{6}{|l|}{ Experimental groups } \\
\hline Anti-NF-M IgG & 161 & $57 \pm 4$ & 104 & $113 \pm 12$ & $<0.005^{*}$ \\
\hline Anti-NF-M Fab & 71 & $61 \pm 3$ & 62 & $99 \pm 8$ & $<0.01 *$ \\
\hline \multicolumn{6}{|l|}{ Control groups } \\
\hline BSA & 79 & $105 \pm 12$ & 73 & $98 \pm 9$ & NS \\
\hline Anti- $\beta$-tubulin & 103 & $123 \pm 8$ & 66 & $126 \pm 8$ & NS \\
\hline Anti- $\beta$-galactosidase & 67 & $148 \pm 18$ & 87 & $121 \pm 6$ & NS \\
\hline \multicolumn{6}{|l|}{ B. $9 \mathrm{hr}$ after plating } \\
\hline Anti-NF-M IgG & 47 & $38 \pm 3$ & 59 & $35 \pm 3$ & NS \\
\hline Anti- $\beta$-galactosidase & 55 & $40 \pm 3$ & 60 & $38 \pm 3$ & NS \\
\hline
\end{tabular}

"For each of the injected substances, six cultures were fixed. Within each culture, camera lucida drawings were made of all injected (i.e., derived from the injected blastomere) and uninjected monopolar neurons that could be distimgiushed easily from neighboring neurons. The length of cach ncuritc was measured, and the lengths for like neuions were then averaged within a single culture dish. The average neurite length for each culture was then averaged over the six separate cultures, and is presented in the table (mean length \pm SEM; $N=6$ cultures).

"The total number of cells in the six cultures that were measured within each group.

The probability that there was no difference between the neurite lengths of injected and uninjected neurons within each group. Significant probabilities $(P<0.05)$ are marked with an asterisk. Insignificant ones are listed as NS. For each culture, the difference in the average lengths of neurites berween injected and uninjected neurons was calculated. These differences were then averaged over the six cultures in each group and compared to the null hypothesis that the difference was zero by a two-tailed $t$ test $(\mathrm{df}=5)$.

FITC-dextran and antibody had no effect on the viability of cultured neurons. On average, each culture had $16 \pm 8$ (mean \pm SD) lys-FITC-DX-positive neurons and $13 \pm 6$ (mean \pm SD) unlabeled neurons. These numbers differed insignificantly.

The presence of antibodies in lys-FITC-DX-labeled neurons during the first day after plating was verified by rhodamine im munofluorescence with anti-mouse $\operatorname{IgG}$ secondary antibodies. Figure 2 shows representative examples of cultured neurons from three such embryos, each injected with a different antibody: anti-Xenopus NF-M $(A-C)$, anti-Xenopus $\beta$ tubulin $(D$ $F$ ), and anti-E. coli $\beta-$ galactosidase $(G-H)$. All three neurons contained both lys-FITC-DX (Fig. $2 B, E, H$ ) and readily detectable levels of the injected antibodics (Fig. $2 C, F, I)$. As determined by the distribution of rhodamine immunofluorescence, the injected antibodies were evenly distributed throughout the full extent of the somas and neurites. Rhodamine immunofluorescent staining of the injected antibodies was robust in lys-FITC-DXlabeled neurons throughout the first day of culture (equivalent through Nieuwkoop and Faber (1956) stage 35/36, which is just after hatching). It was also readily visible during the second day (equivalent through stage 40 , an early swimming tadpole stage), although significantly less intense. By the third day, injected antibodies were no longer detectable. Throughout the first $2 \mathrm{~d}$ of culture, there was a 1:1 correspondence between FITC and rhodamine labeled cells. Since the intensity of the injected antibody was highest during the first day of culture, our observations were made during this period. For example, FITC-labeled neurons of 7 cultures derived from embryos injected with various antibodies were assayed by rhodamine immunofluorescence for the persistence of injected antibodies. These cultures contained a total of 181 FITC-labeled and 142 unlabeled neurons. Every FITC-dextran containing neuron also contained antibody, and vice versa. Thus in subsequent assays, FITC-dextran could be used to identify antibody containing neurons both in living and in fixed cultures.

\section{Injection of anti-NF-M antibody eliminates neurofilaments from neurites}

Neurofilaments are obligate heteropolymers in vivo (Lee et al., 1993). To form viable neurofilaments, NF-M subunits must coassemble with subunits of at least one of the low molecular weight neuronal intermediate filament proteins. Thus if the anti-NF-M antibody altered the cellular distribution of neurofilaments in general, this effect should be detectable with an antibody directed against one of the low molecular weight neurofilament proteins. In addition, the binding of such an antibody to a separate neurofilament subunit would have the added advantage of targeting an epitope separate from that recognized by the injected antibody, thereby reducing any competitive interference between the two antibodies. In mammals, the lower molecular weight neurofilament proteins include NF-L, peripherin and $\alpha$-internexin. In Xenopus embryonic spinal cord neurons, XNIF is the low molecular weight neurofilament protein that first accompanies NF-M (Charnas et al., 1992; Lin and Szaro, 1994). In intact embryos (Szaro et al., 1989) and in culture (Lin and Szaro, 1994), both XNIF and NF-M are expressed soon after neurites emerge (stage 22-26). XNIF expression persists even after NF-L appears, which happens at stage 35/36 in situ and after the first day in culture (Charnas et al., 1992; Lin and Szaro, 1994).

Therefore, to monitor the effects of injected antibodies on the cellular distribution of neurofilaments in general, a rabbit antiserum to XNIF was used in an indirect rhodamine-immunofluorescence assay on cultures fixed $21 \mathrm{hr}$ after plating. In addition to cultures made from embryos injected with anti-NF-M, cultures were also made from embryos injected with BSA, antiXenopus $\beta$-tubulin and anti-E. coli $\beta$-galactosidase, to control for the specificity of the anti-NF-M antibody. In nearly all neurons $(99 \%)$ that contained anti-NF-M antibody, XNIF immunoreactivity failed to enter neurites, regardless of their length 
The Journal of Neuroscience, December 1995, 15(12) 8335
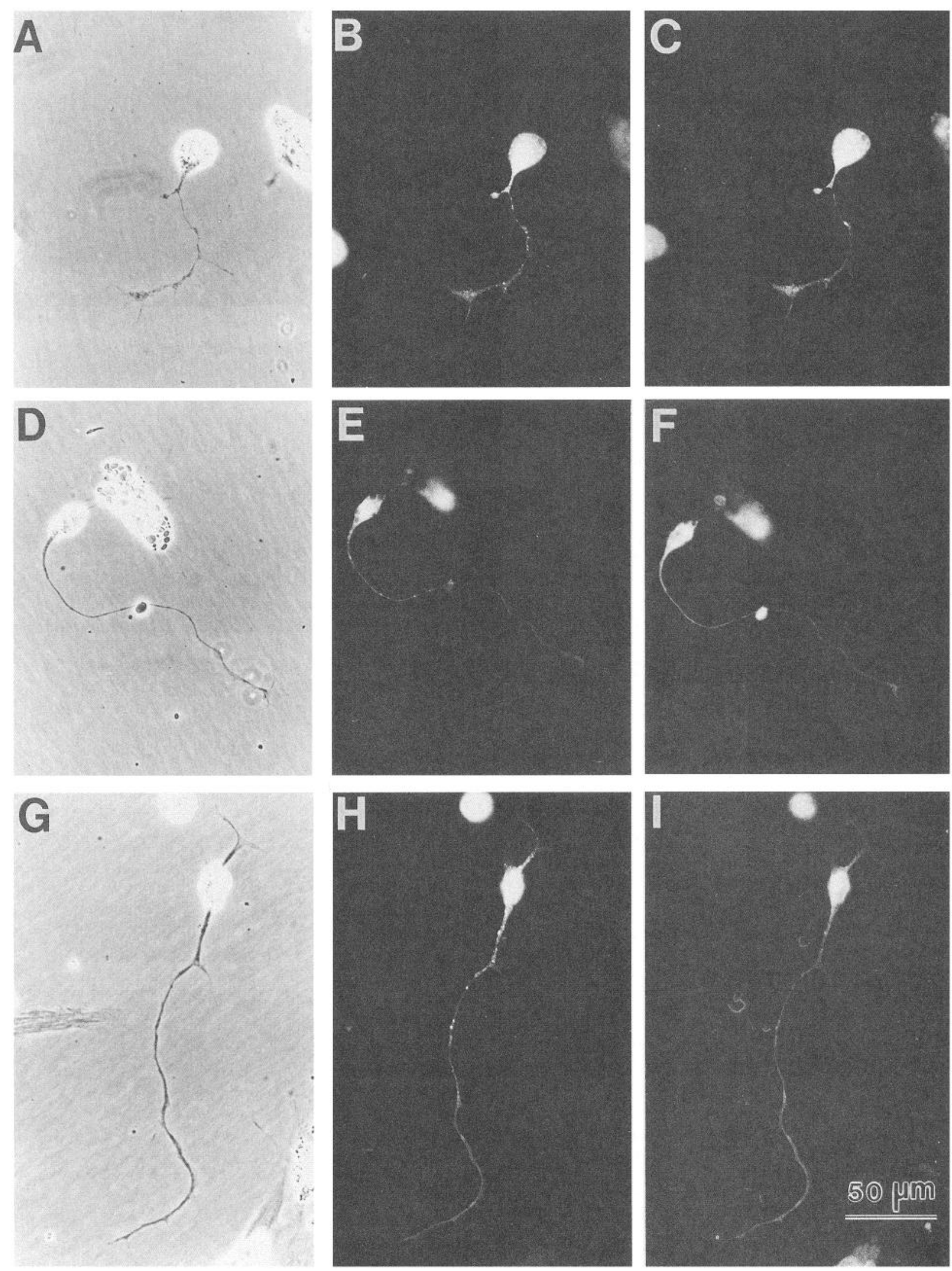

Figure 2. Identification of antibody-containing neurons in cultures, $21 \mathrm{hr}$ after plating. Examples are shown of neurons descended from blastomeres injected with anti-NF-M $(A-C)$, anti- $\beta$ tubulin $(D-F)$, and anti- $\beta$ galactosidase $(G-I)$ monoclonal antibodies. The left three panels $(A, D$, $G)$ show cells viewed by phase contrast microscopy. The middle three panels $(B, E, H)$ show the same cells as in $A, D$, and $G$, respectively, but viewed by fluorescein fluorescence to visualize the FITC-dextran. The right three panels $(C, F, I)$ were the same neurons as in $B, E$, and $H$, respectively, but stained by rhodamine conjugated anti-mouse $\mathrm{IgG}$ and viewed by rhodamine fluorescence to visualize the distribution of the injected antibodies. The scale is the same for all panels. 

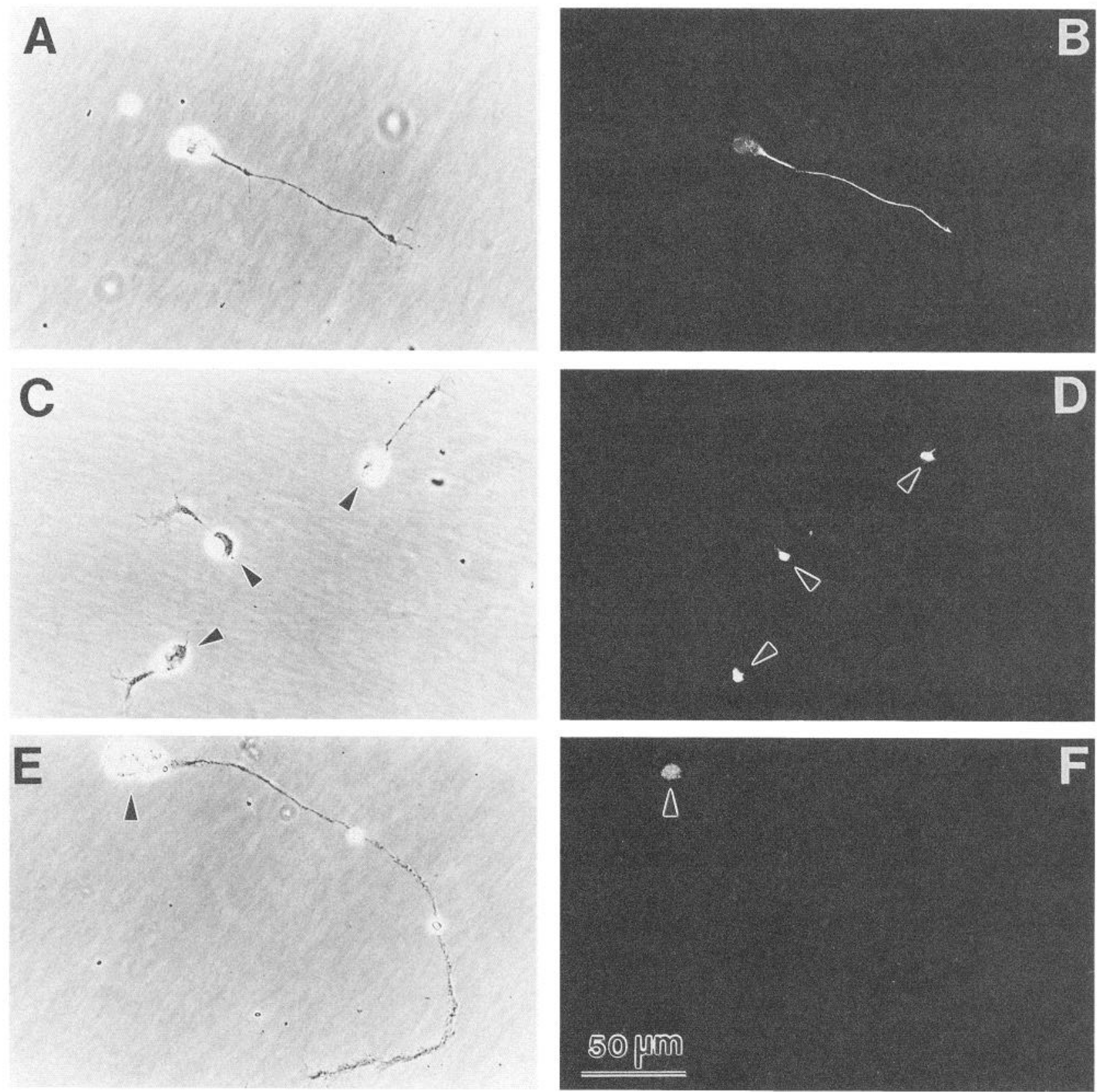

Figure 3. Accumulation of neurofilament protein immunoreactivity in neuronal cell bodies after injection of anti-NF-M monoclonal antibody. The left three panels are cells seen through phase contrast optics and the adjacent right three panels show the same cells stained by the anti-XNIF antibody and viewed by immunofluorescence. $A$ and $B$ show a neuron descended from a blastomere injected with BSA. The XNIF immunoreactivity in the cell body and neurite is distributed as in uninjected neurons. $C-F$ show cells descended from blastomeres injected with the anti-NF-M antibody. In these neurons, the XNIF immunoreactivity has accumulated in the soma (arrowheads in $D$ and $F$ ) and is depleted from the neurites. The scale bar in $F$ indicates the scale for all of the panels.

(illustrated in Fig. $3 C-F$ ). (The remaining $1 \%$ showed only traces of anti-XNIF staining in their neurites near the soma.) In neurons containing anti-NF-M, XNIF immunoreactivity was confined to a small region of the soma, generally some distance from the axon hillock. Normally in uninjected neurons, XNIF immunoreactivity is intense along the neurite and extends to where the shank of the neurite meets the growth cone (Lin and Szaro, 1994). Such a distribution was seen in all neurons containing any of the three control substances. This is illustrated for BSA in Figure $3, A$ and $B$, and for the anti-tubulin and $\beta$-galactosidase injected antibodies in Figure $4 A-D$.

\section{Fab fragments of the anti-NF-M antibody reduce the entry of} neurofilaments into neurites

To help address issues pertaining to the specificity of and mechanism by which the anti-NF-M antibody eliminated neurofilaments from neurites, Fab fragments were prepared from the antiNF-M monoclonal antibody and injected into embryos. Initially, when Fab fragments were injected at the same dose (approximately $100 \mathrm{ng}$ per embryo) as were solutions of whole IgG, the effects on cultured neurons only partially resembled those seen with injections of whole IgG solutions: accumulations of XNIF immunoreactivity formed within the soma, but most neurites 

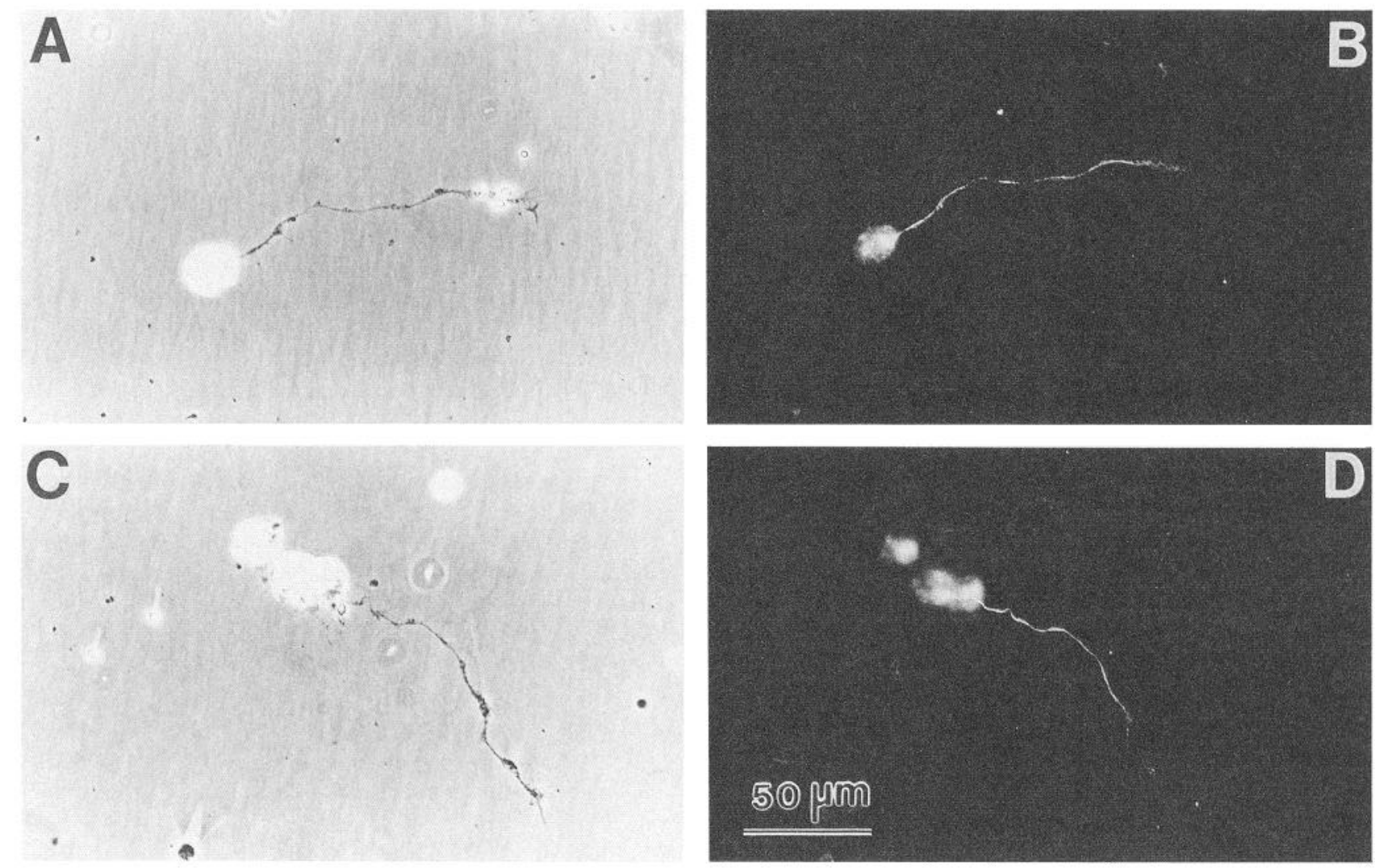

Figure 4. The distribution of XNIF immunoreactivity in control antibody-injected neurons, $21 \mathrm{hr}$ after plating. The left panels show phase contrast views of neurons containing either anti- $\beta$ tubulin $(A)$ or anti- $\beta$ galactosidase $(C)$ monoclonal antibodies. The right panels show the same cell as in $A$ and $C$, respectively, stained by the anti-XNIF antibody and viewed by immunofluorescence. The XNIF immunostaining is distributed within the cell bodies and neurites as in uninjected neurons. The scale, as indicated in $D$, is the same for all panels.

also contained low levels of XNIF immunoreactivity. We verified that Fab fragments persisted in such neurons by immunostaining some with a secondary antibody specific for mouse IgG Fab fragments. An example of such a cell descended from a blastomere injected with 70-100 ng of Fab is shown in Figure $5, A$ and $B$. Note, that as with the other injected antibodies, the Fab fragments are found throughout the cell. When the dose was doubled (150-200 ng per embryo), effects on the distribution of XNIF approached those obtained with solutions of whole IgG. In the best cases, XNIF immunoreactivity was totally confined to the cell body (see Fig. $5 C, D$ ). In 73 neurons scored in six cultures made from embryos injected with Fab fragments of anti-NF-M, XNIF immunoreactivity was completely restricted to the soma in 15 cells $(21 \%)$ and partially confined in 44 cells (60\%). Thus, although not as efficient as whole IgGs, Fab fragments to the anti-NF-M antibody could also restrict the movement of neurofilaments from the cell body into neurites. Because IgGs were more efficient, they were used in most of the subsequent experiments.

\section{Whole IgGs of anti-NF-M had no effect on other cytoskeletal components}

One concern in using an antibody to eliminate neurofilaments from neurites is that the resultant antibody-neurofilament complex might interfere with the movement of other essential components into the neurite. To determine the extent of pleiotrophic effects on microtubules and microfilaments, cultures of embryos injected with whole IgGs to Xenopus NF-M were stained for $\alpha$-tubulin by indirect rhodamine-immunofluorescence and for F-actin by rhodamine-phalloidin.

As shown in Figure 6, the distribution of $\alpha$-tubulin was unaffected by anti-NF-M. Figure $6 B$ shows the distribution of $\alpha$-tubulin that was typical of uninjected neurons, $21 \mathrm{hr}$ after plating. As shown in Figure $6 C-F$, even though anti-NF-M resulted in other abnormalities in neurite shape (which will be discussed later), the distribution of $\alpha$-tubulin was unaffected. In these and all other anti-NF-M containing neurons, $\alpha$-tubulin immunoreactivity was evenly distributed throughout the soma and neurites. This pattern of $\alpha$-tubulin immunoreactivity lacked any evidence of either an accumulation of tubulin in the soma or a depletion of it from the proximal neurite, which would be expected if the anti-NF-M-neurofilament complex had blocked tubulin transport into the neurite. Interestingly, as shown in Figure $6 H$, injection of the anti-Xenopus $\beta$-tubulin antibody also failed to have any effect on the distribution of $\alpha$-tubulin. Although this antibody recognizes Xenopus $\beta$-tubulin (Klymkowsky et al., 1987; Chu and Klymkowsky, 1989), it has no effect on development through gastrulation after injection into Xenopus embryos (Klymkowsky et al., 1992). Thus, binding of a divalent antibody to a cytoskeletal structure does not necessarily produce deleterious cross-linking of polymers.

As shown in Figure 7, microinjection of anti-NF-M also failed to have any effect on the subsequent distribution of F-actin in neurons. In normal uninjected neurons (Fig. 7B), F-actin staining by phalloidin is found primarily in the growth cone and sporadically within the soma and along the neurite. The latter staining 

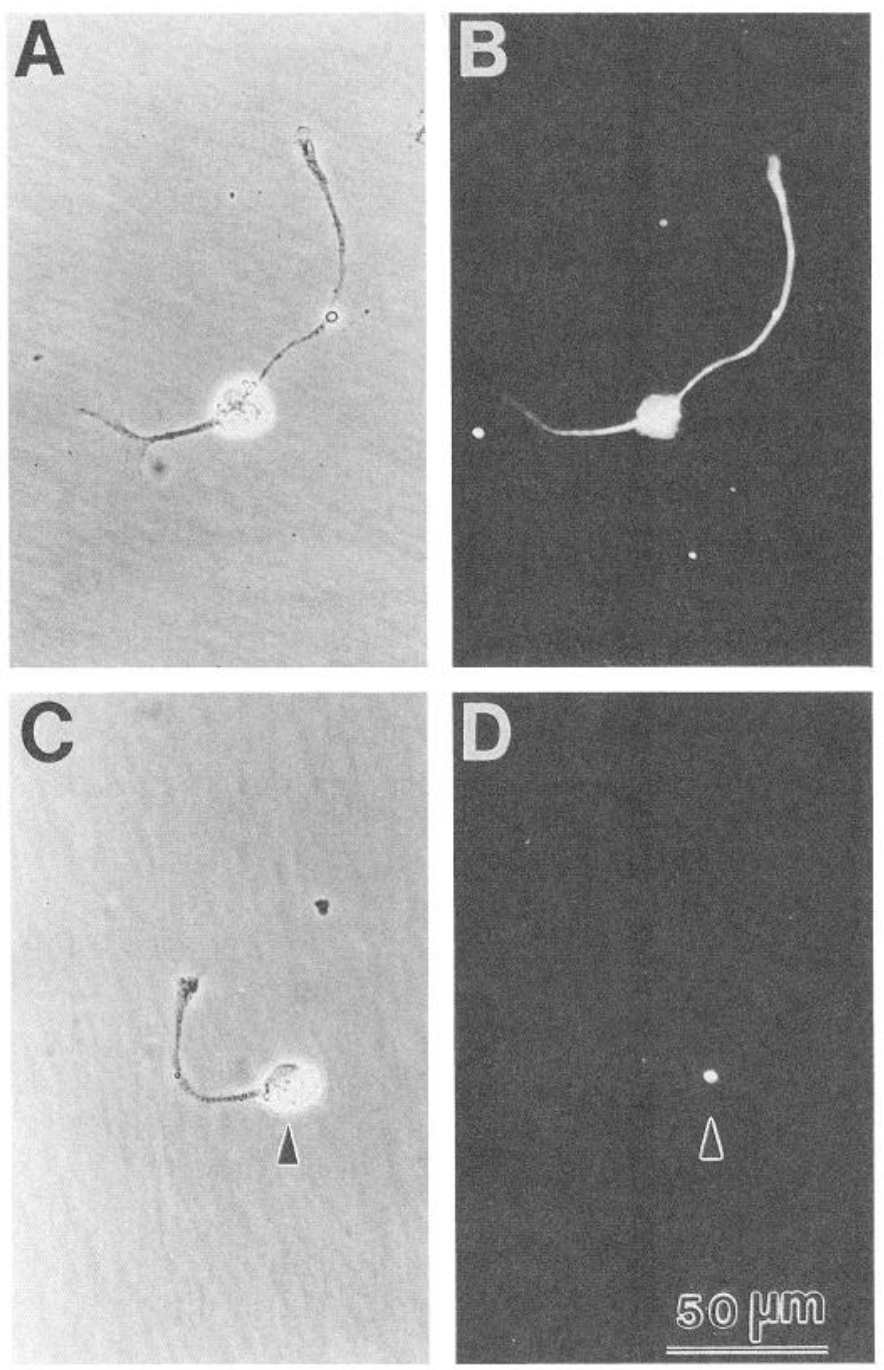

Figure 5. The effect of injection of Fab fragments of the anti-NF-M antibody. $B$ shows the distribution of Fab fragments in a neuron, $21 \mathrm{hr}$ after plating, that was descended from a blastomere injected with Fab fragments. The distribution of Fab fragments is visualized by immunofluorescence after the neuron was stained with anti-mouse IgG-Fab. $D$ shows the distribution of XNIF immunoreactivity in a neuron descended from a blastomere injected with Fab fragments. XNIF immunoreactivity is concentrated in the cell body (arrowhead) and absent from the neurite. $A$ and $C$ show the same neurons as in $B$ and $D$, respectively, but viewed under phase contrast conditions. The scale bar in $D$ applies to all panels.

represents points of attachment between the cell and the culture dish. In cultured neurons containing anti-NF-M, the distribution of rhodamine-phalloidin staining was indistinguishable from that of uninjected neurons (Fig. $7 D$ ). These data helped to argue further that the effects of the anti-NF-M antibody were due to a lack of neurofilaments rather than from pleiotrophic effects resulting from blockage of materials from entering the neurite.

\section{In neurites, anti-NF-M reduced the rate of elongation and resulted in a range of abnormal morphologies}

The data presented in the previous sections showed that during the first day in culture the microinjected anti-NF-M antibody successfully eliminated neurofilaments from neurites without noticeably disturbing the normal distributions of microtubules and microfilaments. In this section, we demonstrate that neurites without neurofilaments elongated less and displayed a variety of abnormal morphological features.

In Xenopus dissociated neural tube cultures, neuronal survival and neurite outgrowth are greatest during the first $2 \mathrm{~d}$ of culture. Since levels of the injected antibodies were highest during the first day of culture, neurite lengths were initially examined during this period. These data are presented in Table 1. The first group examined consisted of neurons at $21 \mathrm{hr}$ after plating (Table 1A). For each antibody injected, the primary neurites were measured from camera lucida tracings of each monopolar neuron, either FITC-labeled or unlabeled, that was sufficiently isolated to allow it to be traced without confusing it with other neurons. In the case of neurons containing anti-NF-M, which possessed numerous thin collateral processes not found on normal neurons, only the length of the primary neurite from soma to growth cone was measured. The average neuritic length was calculated separately for the FITC-labeled or unlabeled neurons in each culture, and these averages were then averaged over six cultures for a two-tailed paired $t$ test (Sachs, 1984). At $21 \mathrm{hr}$ after plating, the neurites of neurons derived from blastomeres injected with whole IgG anti-NF-M were approximately half as long as those of their unlabeled sibling neurons. Fab fragments of anti-NF-M also significantly reduced neurite lengths at $21 \mathrm{hr}$ after plating, although not as much as whole IgGs did. For all of the control groups (BSA, anti- $\beta$-tubulin, anti- $\beta$-galactosidase), the differences in neuritic lengths were insignificant. At $9 \mathrm{hr}$, however, the effect of anti-NF-M on neurite lengths was insignificant (Table 1B). Thus, the shorter neurites of anti-NF-M antibody containing neurons arose as the result of reduced neuritic elongation between 9 and $21 \mathrm{hr}$ rather than from a delay in the initiation of neurite outgrowth.

At $21 \mathrm{hr}$ of culture, neurites of neurons containing the injected anti-NF-M antibody were morphologically abnormal in approximately half of the cases. Of 238 cells containing anti-NF-M antibody that were scored (7 cultures), the neurites of 101 of them were clearly abnormal. Normal neurites are typically less than $3 \mu \mathrm{m}$ in diameter, with occasional varicosities extending small (generally less than 10-12 $\mu \mathrm{m}$ long) filopodia and a single growth cone that is easily distinguishable from the rest of the neurite. Figure $8 A-E$ contains examples of control neurons with typically normal neurites. Figure $8 F$ shows a representative example of one of the 137 neurons containing anti-NF-M that was morphologically indistinguishable from control cells. Figure $8 G-J$ shows representative examples illustrating the variety of abnormalities typical of the other neurons containing anti-NFM. Other examples are shown in Figure $6, C$ and $E$. We believe that the range of effects, at least in part, resulted from the heterogeneity of neurons found in these cultures; based on the anatomical location of somas and direction of axonal projections, at least nine different types of neurons have been identified in the Xenopus laevis embryonic spinal cord (Roberts and Clarke, 1982). Another possibility is that the defects observed at $21 \mathrm{hr}$ represented an early stage in the formation of defective neurites. One of the most obvious defects was that the diameters of many neurites containing anti-NF-M varied along their lengths. Some tapered to a fine process (Fig. $8 G, H$ ), whereas others were broader, with diameters as large as $6 \mu \mathrm{m}$ (Fig. 8I,J). In addition, affected neurons extended numerous collateral processes (Fig. $8 G-J)$. In some cases, these processes were thin, exceeding 15 $\mu \mathrm{m}$ in length and with multiple branches (Fig. $8 G, H$ ). Other processes formed behind extensive growth cones (Fig. 8I,J). Thus, neurofilaments appeared to help define the stereotypical 

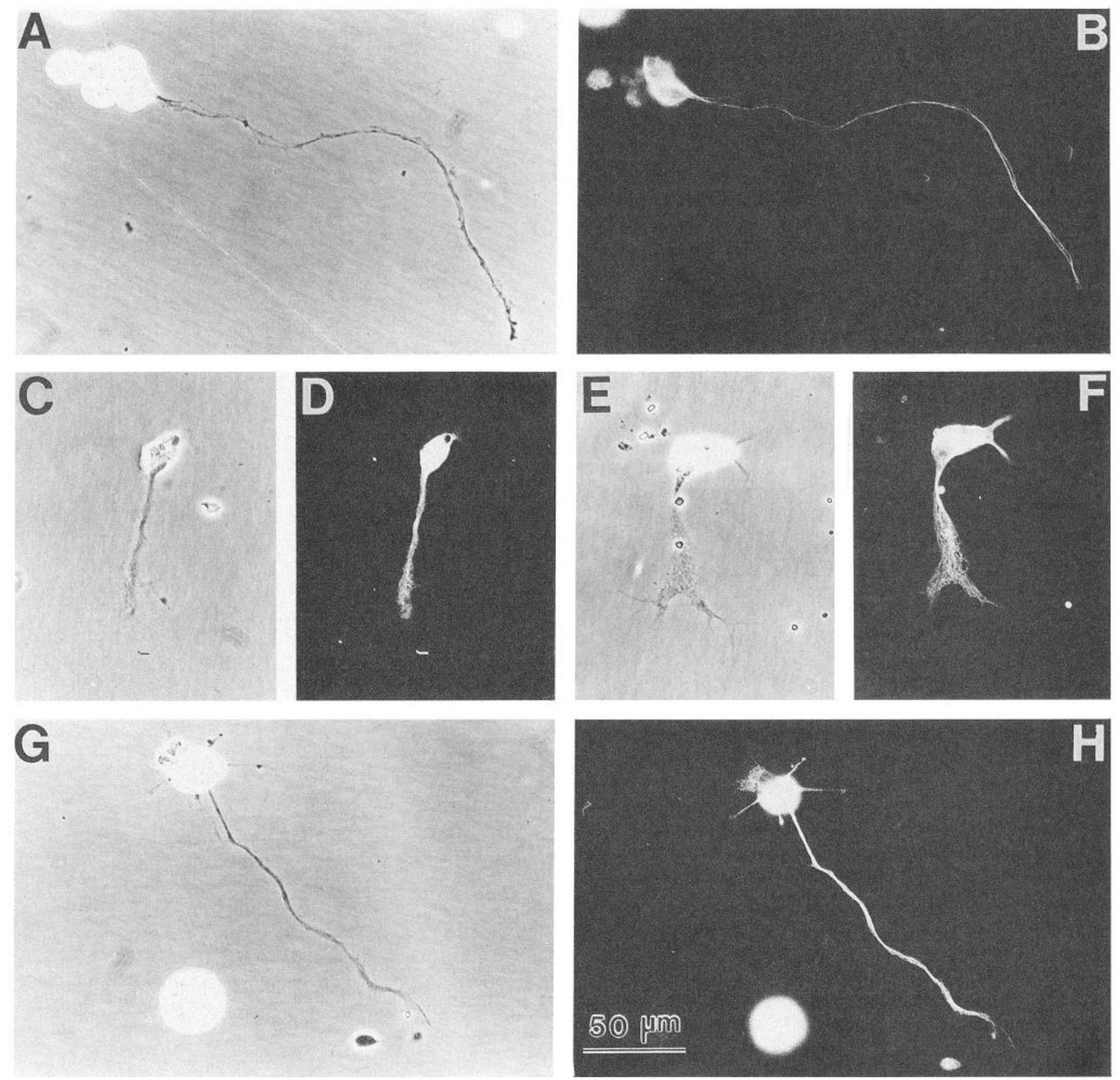

Figure 6. The distribution of $\alpha$-tubulin immunoreactivity in neurons descended from an uninjected blastomere $(A, B)$ and from blastomeres injected with either anti-NF-M $(C-F)$ or anti- $\beta$-tubulin $(G, H)$ monoclonal antibodies. Cells are from cultures, $21 \mathrm{hr}$ after plating. $A$, $C, E$, and $G$ show neurons photographed through phase contrast optics. $B, D, F$, and $H$ show these same neurons stained with anti- $\alpha$-tubulin and viewed by immunofluorescence. The scale bar in $H$ indicates the scale for all of the panels.

shapes of normal Xenopus cultured neurites, probably by contributing to their structural strength.

\section{Discussion}

These experiments demonstrated the utility of using Xenopus embryos to directly manipulate the neurofilament content of developing axons in culture. Our results were consistent with the hypothesis that neurofilaments provide mechanical support that enhances the structural integrity of these neurites. Injection of a monoclonal antibody against Xenopus NF-M into a single embryonic blastomere at the 2-cell stage subsequently confined all neurofilament immunoreactivity to the somas and prevented neurofilaments from entering the neurites. Prior to $9 \mathrm{hr}$ in culture, neurites of neurons descended from anti-NF-M injected blastomeres were normal in length; but by $21 \mathrm{hr}$, such neurites were only half as long as controls. At that time, nearly half the neurites lacking neurofilaments also exhibited marked morphological defects. These included uneven widths of neurites, poorly defined separations between the growth cone and neurite, and more extensive collateral branching along the length of the neurite. All of these defects were consistent with a reduced capacity for neurites lacking neurofilaments to resist the increasing mechanical stresses imposed on them as they elongate. Previous observations that neuritic growth rates slow down as neurofilaments emerge within developing neurites led to the conclusion that neurofilaments act to consolidate the cytoskeleton of the 

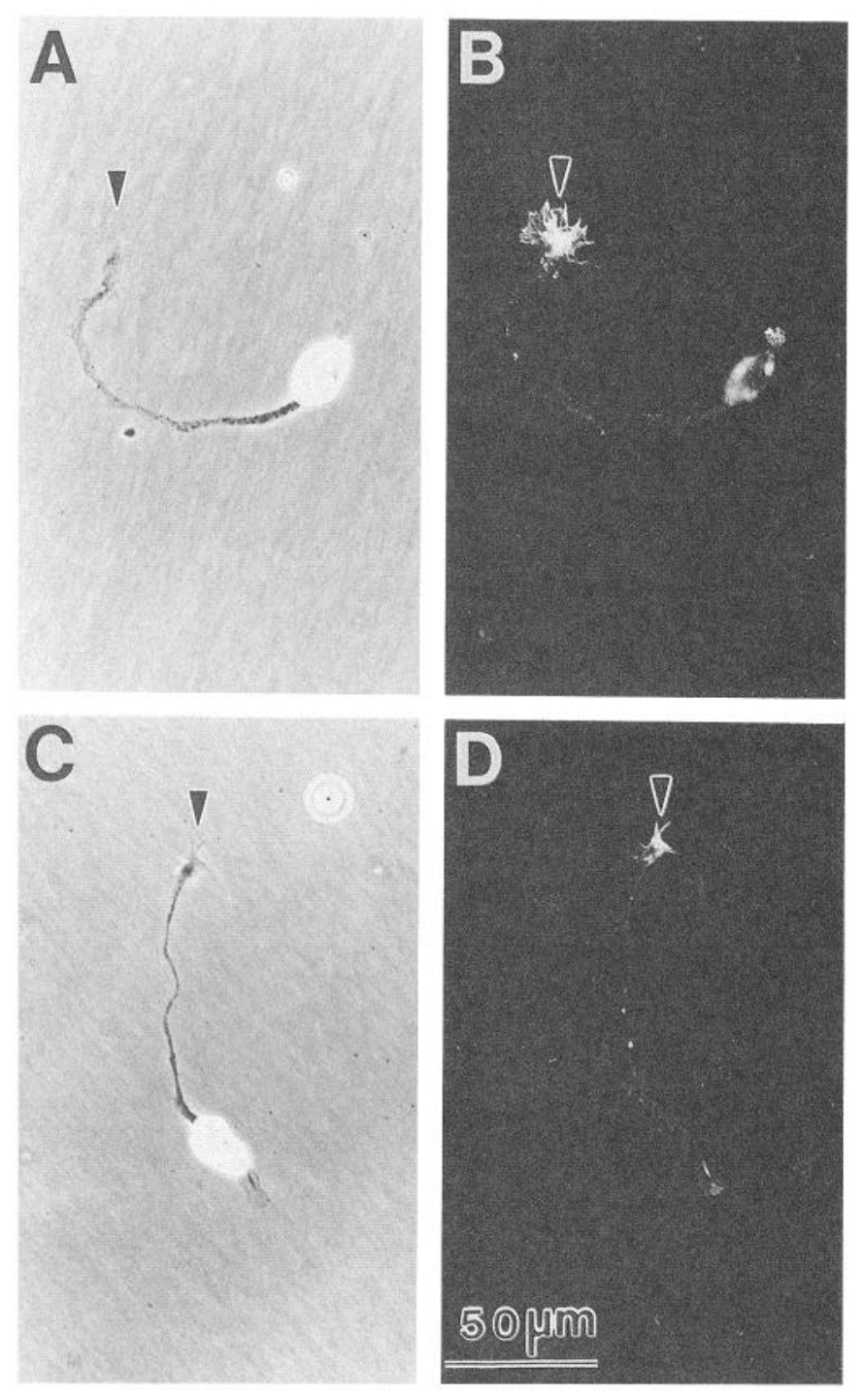

Figure 7. The distribution of F-actin in a neuron descended from an uninjected blastomere $(A, B)$ and from a blastomere injected with antiNF-M antibody $(C, D)$. $A$ and $C$ are photomicrographs taken with phase contrast optics; $B$ and $D$ show the same neurons, respectively, stained for F-actin with rhodamine-phalloidin and viewed by fluorescence. Phalloidin staining of F-actin is most abundant in the growth cone ( $\mathrm{ar}$ rowhead). Patches of staining seen along the neurites may indicate positions where neurites are attached to the culture substrate. The scale, indicated in $D$, is the same for all panels.

growing axon (Oblinger and Lasek, 1984; Oblinger et al., 1989a). Our results, while consistent with this interpretation, further suggest the possibility that neurofilaments assist developing neurites to exceed a critical size by providing supplemental mechanical support.

This critical size should vary among neurites depending both on the amount of other mechanical support that is normally pro- vided by the microfilaments and microtubules, and on the physical forces that stress the neuron. In the intact embryo, this idea is supported indirectly by observations that neurofilament content varies widely among different axons. For example, in Xenopus embryos, optic axons growing inside the head along the optic pathway express no detectable neurofilaments until entering the tract; whereas motor axons, which are undoubtedly exposed to more physical stress while crossing the space between the neural tube and somites, are filled with neurofilaments to their growth cones (Szaro et al., 1989). In culture, the various types of neurons present (Roberts and Clarke, 1982) would be expected to adhere differentially to the culture substrate. If so, this could explain why some neurites were more severely affected than others.

These experiments complemented previous ones performed on intact Xenopus embryos (Szaro et al., 1991). In those experiments, injected neurofilament antibodies significantly reduced the extent of peripheral axonal outgrowth. The similarities of these two sets of results increase our confidence in the relevance of these experiments to our general understanding of the function of neurofilaments in young axons. The culture experiments produced the further advantage of enabling us to observe isolated sibling experimental and control neurons derived from the same animal and grown in identical conditions. We were thus able to demonstrate convincingly that neurofilament immunoreactivity was completely eliminated from neurites and to observe directly the adverse effects that the injected antibody had on neuritic elongation and morphologies. In the future, it should be possible to follow these effects on individual neurons, dynamically, in real time.

One possible caveat that could be raised against our interpretation of the data is that accumulations of neurofilaments might nonspecifically block the transport of materials necessary for maintaining normal axonal growth. Indeed in transgenic mice experiments, expression of mutated neurofilament proteins has led to neurodegeneration caused by blockages in the proximal axon formed by accumulating neurofilaments (Cote et al., 1993; Xu et al., 1993; Figlewicz et al., 1994; Lee et al., 1994; Collard et al., 1995). However, not all accumulations of neurofilaments necessarily result in neurodegeneration. For example, other transgenic mice that postnatally express a NF-H/ $\beta$-galactosidase fusion protein have somatic accumulations of neurofilaments that never enter the axon. Although the axons of these mice are small in caliber, they persist throughout the life of the animal and show no evidence of defective axonal transport (Eyer and Peterson, 1994). Thus, the key factor responsible for neurodegeneration seems to be the formation of tangles of neurofilaments within the axon itself (Lee et al., 1994; Figlewicz et al., 1994; Collard et al., 1995). In our culture experiments, neurofilament accumulations were found in the cell bodies, not in the neurite. The uniform distributions of injected neurofilament antibody (Fig. 2) and $\alpha$-tubulin immunostaining (Fig. 6) in affected neurites and the normal distributions of F-actin (Fig. 7) provided

Figure 8. Effects of anti-NF-M antibody injection on neurite appearance. The left five panels $(A-E)$ show neurons from control groups. These include two uninjected neurons $(A, B)$, and neurons descended from blastomeres injected with BSA $(C)$, anti- $\beta$-tubulin $(D)$ or anti- $\beta$-galactosidase $(E)$. The adjacent right panels $(F-J)$ show neurons representative of the range of morphologies seen in cells containing anti-NF-M antibody. Whereas neurons from control groups had long uniform neurites with well-defined growth cones, neurons filled with neurofilament antibody had neurites exhibiting a variety of shapes. For example, the neuron in $F$ is normal. The neurites of the neurons in $G$ and $H$ have uneven diameters and abnormally long minor collateral processes emanating from the middle of the neurite. The neurites of the cells in $I$ and $J$ are aberrantly broad with collateral processes ending in extensive growth cones. The scale bar in $J$ applies to all panels. 

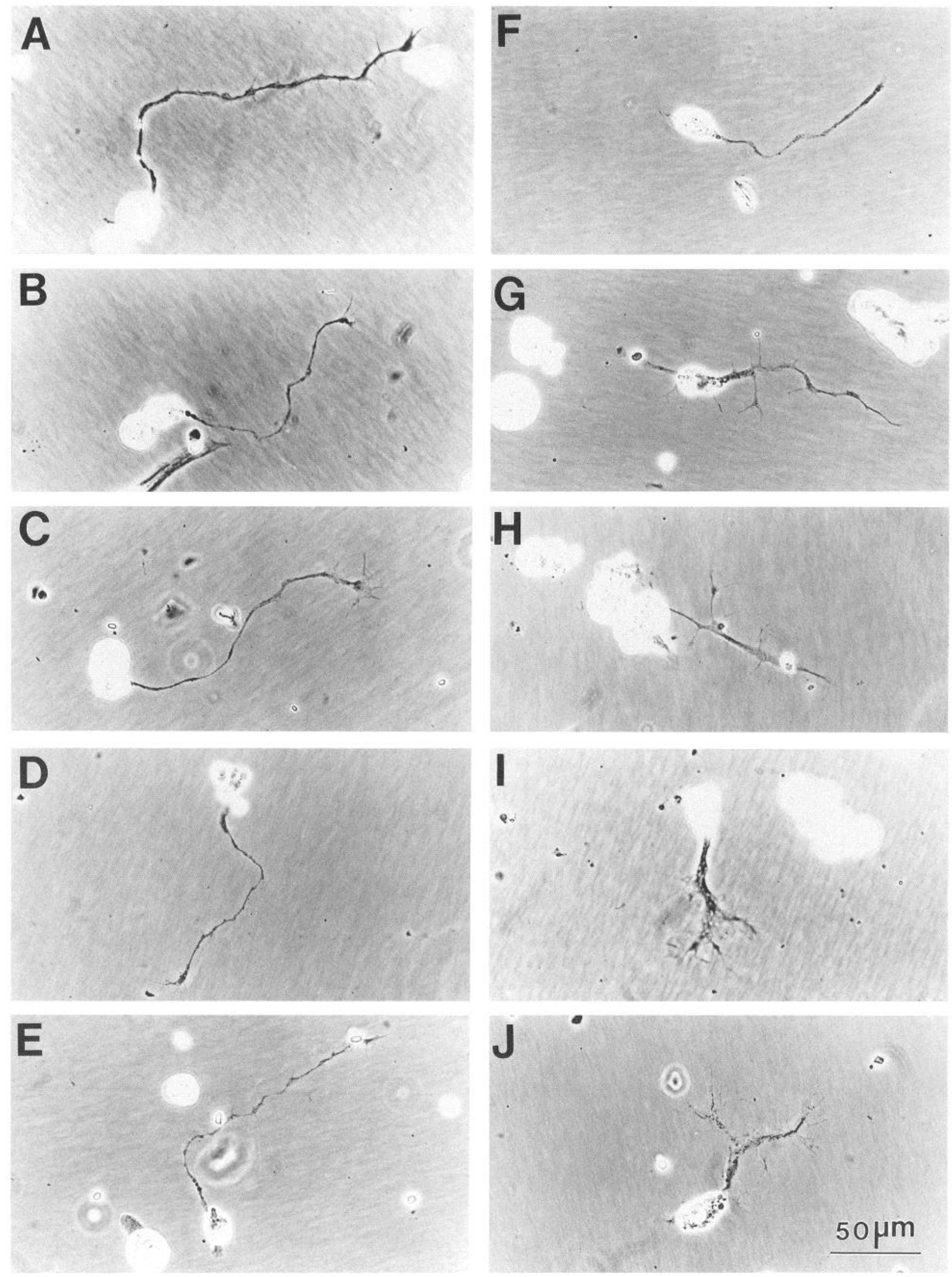
even more compelling evidence that the effects we observed were caused directly by the lack of neurofilaments within neurites. Furthermore, the lack of buildup of these other materials at the sites of the somatic neurofilament accretions argued further that movement of structural materials into the neurites was unimpeded. In addition, injection of a whole IgG molecule directed against Xenopus $\beta$-tubulin had no effect on neurite outgrowth, despite the expectation that the bivalent antibodies might cross-link this other cytoskeletal polymer and inhibit intracellular traffic. Indeed, monovalent Fab fragments of the antiNF-M antibody XC10C6 could produce effects similar to those observed with whole bivalent IgG molecules, although the Fabs were less efficient. Both whole IgGs and Fabs could inhibit the movement of XNIF immunoreactivity into the axon, suggesting that the antibody produced its effect by sterically hindering interactions between neurofilaments and the transport mechanism instead of by cross-linking the neurofilaments. This could have occured either by inhibiting the exchange of neurofilament protein subunits between the assembled filaments and the transport machinery (Nixon and Shea, 1992; Takeda et al., 1994) or by directly interfering with the movement of partially assembled polymers into the developing neurite. One reason that the Fab fragments were less efficient than whole IgGs could be that because the Fabs were smaller, they provided less steric hindrance than whole IgGs. This would suggest further that the site of XC10C6 binding to NF-M is some distance away from the site of interaction between NF-M and the transport machinery.

The effects of depriving developing Xenopus axons of neurofilaments were consistent with those observed for other intermediate filaments in development. For example, the elimination of cytokeratins from developing Xenopus laevis embryos by either antibodies or antisense oligonucleotides results in poor wound healing and a tendency for embryos to gastrulate abnormally (Klymkowsky et al., 1992; Torpey et al., 1992), but otherwise allows normal embryogenesis to proceed. Suppressing the expression of glial fibrillary acidic protein (GFAP) in an astrocytic cell line inhibits the extension of stable, long astrocytic processes (Weinstein et al., 1991). Loss of human cytokeratin 14 compromises the structural integrity of skin (Chan et al., 1994). Introduction of neurofilament antibodies into a neuronal cell line that is induced to differentiate significantly reduces the stability of neurites without reducing the number of neurites initially extended (Shea and Beermann, 1994). Thus, enhancing the mechanical strength and stability of developing tissues rather than directing growth appears to be a generalized function of intermediate filament proteins.

One of the hallmark features of intermediate filament proteins is that their molecular composition varies as a function of both cell type and stage of maturation. The unique intermediate filament protein composition of different tissues at various stages of development probably reflects the changing structural demands placed upon cells. In adults, for example, the calibers of myelinated peripheral axons are modulated through enhancements in neurofilament content. This conclusion is based on the observations that calibers of normal (Friede and Samorajski, 1970) and regencrating peripheral axons (Clcveland ct al., 1991; Muma et al., 1991) vary directly with neurofilament content. Animals whose adult axons entirely lack neurofilaments have provided direct proof for a causal relationship between neurofilament content and axonal caliber. Peripheral myelinated axonal caliber is significantly reduced both in the quiverer mutant Japanese quail, which lacks neurofilaments because of a loss of
NF-L (Yamasaki et al., 1991), and in a transgenic mouse lacking axonal neurofilaments due to the expression of a dominant negative NF-H/ $\beta$-galactosidase fusion protein (Fyer and Peterson, 1994). This dependence of adult axonal caliber on neurofilaments may result from the expression of highly phosphorylated NF-H (Lee and Cleveland, 1994). Embryonic axons, which have significantly smaller calibers, are characterized by lower neurofilament contents (Schwartz et al., 1990), an absence of phosphorylated forms of NF-H and NF-M (Shaw and Weber, 1982; Charnas et al., 1992; Carden et al., 1987; Dahl et al., 1989; Szaro et al., 1989; Schwartz et al., 1990; Zhao and Szaro, 1994), and the expression of various alternate forms of low molecular weight neuronal intermediate filament proteins (Oblinger et al., 1989b; Troy et al., 1990; Charnas et al., 1992; Glasgow et al., 1992, 1994; Fliegner et al., 1994). Indeed, the progressive changes and variations in neurofilament composition that occur during development among different types of neurons imply that the utility of neurofilaments must vary. Whereas some neurons express very few neurofilaments during the earliest phases of axonal outgrowth (Tetzlaff and Bisby, 1989; Zhao and Szaro, 1994) and may even lack neurofilaments altogether in adults (Burton and Wentz, 1992), other growing axons are filled with neurofilaments to their growth cones and actively modulate the molecular composition of their neurofilaments locally within the axon (Szaro et al., 1989; Landmesser and Swain, 1992). Many of these changes are actively regulated successively by interactions between growing axons and their substrates (Landmesser and Swain, 1992; Liuzzi and Tedeschi, 1992; Glasgow et al., 1994; Hall, 1994; Zhao and Szaro, 1995), which further emphasizes their importance in axonal development.

Neurofilaments cannot, however, be an absolute requirement for axonal formation per se. For example, the quiverer quails are nevertheless viable without neurofilaments, despite thinner, fewer axons and a trembling phenotype (Yamasaki et al., 1991). The viability of the mutants contrasted against their quivering phenotype implies that neurofilaments are the supportive cytoskeletal element of developing axons rather than the pioneering component driving axonal growth, but nonetheless their role has become essential for normal neural development. The successive transformations in neurofilament composition that occur during axonal development may therefore serve to modulate axonal structural strength, which would accomodate axons' changing requirements for mechanical stability. Our results show what can happen to a group of embryonic neurons whose growing axons are deprived of their normal complement of neurofilaments. Through the injection of mRNAs into Xenopus blastomeres to obtain early expression of proteins (Vize et al., 1991), this system should next prove useful for studying the effects on growing neurites of prematurely expressing those neurofilament proteins indicative of more mature axons.

\section{References}

Allen RD, Weiss DG, Hayden JH, Brown DT, Fujiwaki H, Simpson M (1985) Gliding movement of and bidirectional organelle transport along single native microtubules from squid axoplasm: evidence for an active role of microtubules in cytoplasmic transport. J Cell Biol 100:1736-1752.

Anderson MJ, Cohen MW, Zorychta E (1977) Effects of innervation on the distribution of acetylcholine receptors on cultured muscle cells. J Physiol (Lond) 268:731-756.

Burton PR, Wentz MA (1992) Neurofilaments are prominent in bullfrog olfactory axons but are rarely seen in those of the tiger salamander, Ambystoma tigrinum. J Comp Neurol 317:396-406.

Carden MJ, Trojanowski JQ, Schlaepfer WW, Lee VM-Y (1987) Two- 
stage expression of neurofilament polypeptides during rat neurogenesis with early establishment of adult phosphorylation patterns. J Neurosci 7:3489-3504.

Chan Y, Anton-Lamprecht I, Yu Q-C, Jackel $\Lambda$, Zabel B, Ernst J-P, Fuchs E (1994) A human keratin 14 "knockout": the absence of K14 leads to severe epidermolysis bullosa simplex and a function for an intermediate filament protein. Genes Dev 8:2547-2587.

Charnas LR, Szaro BG, Gainer H (1992) Identification and developmental expression of a novel low molecular weight neuronal intermediate filament protein in Xenopus laevis. J Neurosci 12:30103024

Chu DTW, Klymkowsky MW (1989) The appearance of acetylated alpha-tubulin during early development and cellular differentiation in Xenopus. Dev Biol 136:104-117.

Cleveland DW, Monteiro MJ, Wong PC, Gill SR, Gearhart JD, Hoffman PN (1991) Involvement of neurofilaments in the radial growth of axons. J Cell Sci 15:85-95.

Cohen MW, Rodriguez-Marin E, Wilson EM (1987) Distribution of synaptic specializations along isolated motor units formed in Xenopus nerve-muscle cultures. J Neurosci 7:2849-2861.

Cole JS, Messing A, Trojanowski JQ, Lee VM-Y (1994) Modulation of axon diameter and neurofilaments by hypomyelinating Schwann cells in transgenic mice. J Neurosci 14:6956-6966.

Collard J-F, Cote F, Julien J-P (1995) Defective axonal transport in a transgenic mouse model of amyotrophic lateral sclerosis. Nature 375: $61-64$.

Cote F, Collard J-F, Julien J-P (1993) Progressive neuronopathy in transgenic mice expressing the human neurofilament heavy gene: a mouse model of amyotrophic Iateral sclerosis. Cell 73:35-46.

Dahl D, Bignami A (1986) Neurofilament phosphorylation in development: a sign of axonal maturation? Exp Cell Res 162:220-230.

Dahl D, Labkovsky B, Bignami A (1989) Early and late appearance of neurofilament phosphorylation events in nerve regeneration. Brain Res Bull 22:225-232.

Dent JA, Polson AG, Klymkowsky MW (1989) A wholemount immunocytochemical analysis of the expression of the intermediate filament protein vimentin in Xenopus. Development 105:61-74.

Eyer J, Peterson A (1994) Neurofilament-deficient axons and perikaryal aggregates in viable transgenic mice expressing a neurofilamentbeta-galacotsidase fusion protein. Neuron 12:389-405.

Eyer J, McClean WG, Leterrier JF (1989) Effect of a single dose of beta,beta'-iminodipropionitrile in vivo on the properties of neurofilaments in vitro: comparison with the effect of iminodipropionitrile added directly to neurofilaments in vitro. J Neurochem 52:17591765 .

Figlewicz DA, Krizus A, Martinoli MG, Meininger V, Dib M, Rouleau GA, Julien J-P (1994) Variants of the heavy nerofilament subunit are associated with the development of amyotrophic lateral sclerosis. Human Mol Gen 3:1757-1761.

Fliegner KH, Kaplan MP, Wood TL, Pintar JE, Liem RKH (1994) Expression of the gene for the neuronal intermediate filament protein alpha-internexin coincides with the onset of neuronal differentiation in the developing rat nervous system. J Comp Neurol 342:161-173.

Fricde RL, Samorajski T (1970) Axon caliber related to neurofilaments and microtubules in sciatic nerves of rats and mice. Anat Rec 167: 379-388.

Glasgow E, Druger RK, Levine EM, Fuchs C, Schechter N (1992) Plasticin, a novel type III neurofilament protein from goldfish retina: increased expression during optic nerve regeneration. Neuron 9:373381 .

Glasgow E, Druger RK, Fuchs C, Lane WS, Schechter N (1994) Molecular cloning of gefiltin (ON1): serial expression of two new neurofilament mRNAs during optic nerve regeneration. EMBO J 13:297305 .

Gurdon JB (1967) African clawed frogs. In: Methods in developmental biology (Wilt FH, Wessels NK, eds), pp 75-84. New York: Crowell.

Hall CM (1994) Differential regulation of two classes of neuronal intermediate filament proteins during optic nerve regeneration. J Neurochem 63:2307-2313

Hirose G, Jacobson M (1979) Clonal organization of the central nervous system of the frog. I. Clones stemming from individual blastomeres of the 16-cell and earlier stages. Dev Biol 71:191-202.

Hoffman PN, Cleveland DW, Griffin JW, Landes PW, Cowan NJ, Price DL (1987) Neurofilament gene expression: a major determinant of axonal caliber. Proc Natl Acad Sci USA 84:3472-3476.
Hoperskaya OA (1975) The development of animals homozygous for a mutation causing periodic albinism ( $\mathrm{a}^{\mathrm{p}}$ ) in Xenopus laevis. J Embryol Exp Morphol 34:253-264.

Klymkowsky MW, Maynell LA, Polson AG (1987) Polar asymmetry in the organization of the cortical cytokeratin system of Xenopus laevis oocytes and embryos. Development 100:543-557.

Klymkowsky MW, Shook DR, Maynell LA (1992) Evidence that the deep keratin filament systems of the Xenopus embryo act to ensure normal gastrulation. Proc Natl Acad Sci USA 89:8736-8740.

Landmesser L, Swain S (1992) Temporal and spatial modulation of a cytoskeletal antigen during peripheral axonal pathfinding. Neuron $8: 291-305$

Lee MK, Cleveland DW (1994) Neurofilament function and dysfunction: involvement in axonal growth and neuronal disease. Curr Opinion Cell Biol 6:34-40.

Lee MK, Xu Z, Wong PC, Cleveland DW (1993) Neurofilaments are obligate heteropolymers in vivo. J Cell Biol 122:1337-1350.

Lee MK, Marszalek JR, Cleveland DW (1994) A mutant neurofilament subunit causes massive, selective motor neuron death: implications for the pathogenesis of human motor neuron disease. Neuron 13:975988.

Leterrier JF, Eyer J (1987) Properties of highly viscous gels formed by neurofilaments in vitro: a possible consequence of a specific interfilament cross-bridging. Biochem J 245:93-101.

Lin W, Szaro BG (1994) Maturation of neurites in mixed cultures of spinal cord neurons and muscle cells from Xeropus laevis embryos followed with antibodies to neurofilament proteins. J Neurobiol 25: $1235-1248$.

Liuzzi FJ, Tedeschi B (1992) Axo-glial interactions at the dorsal root transitional zone regulate neurofilament protein synthesis in axotomized sensory neurons. J Neurosci 12:4783-4792.

Mitchison T, Kirschner M (1988) Cytoskeletal dynamics and nerve growth. Neuron 1:761-772.

Muma NA, Slunt HH, Hoffman PN (1991) Postnatal increases in neurofilament gene expression correlate with the radial growth of axons. J Neurocytol 20:844-854.

Nieuwkoop PD, Faber J (1956) Extenal and internal stage criteria of the development of Xenopus laevis. In: Normal table of Xenopus laevis (Daudin) (Nieuwkoop PD, Faber J, eds), pp 162-188. Amsterdam: North-Holland.

Nixon RA, Shea TB (1992) Dynamics of neuronal intermediate filaments: a developmental perspective. Cell Motil Cytoskel 22:81-91.

Oblinger MM, Lasek RJ (1984) A conditioning lesion of the peripheral axons of dorsal ganglion cells accelerates regeneration of only their peripheral axons. J Neurosci 4:1736-1744.

Oblinger MM, Szumlas RA, Wong J, Liuzzi FJ (1989a) Changes in neurofilament gene expression affect the composition of regenerating axonal sprouts elaborated by DRG neurons in vivo. J Neurosci 9:2645-2653.

Oblinger MM, Wong J, Parysek LM (1989b) Axotomy-induced changes in the expression of a type III neuronal intermediate filament. J Neurosci 9:3766-3775.

Pachter JS, Liem RKH (1984) The differential appearance of neurofilament triplet polypeptides in the developing rat optic nerve. Dev Biol 103:200-210.

Parhad IM, Clark NW, Griffin JW (1987) Effect of changes in neurofilament content on caliber of small axons: the beta-beta' iminodipropionitrile model. J Neurosci 7:2256-2263.

Roberts A, Clarke JDW (1982) The neuroanatomy of an amphibian embryo spinal cord. Philos Trans R Soc Lond [Biol] 296:195-212.

Sachs L (1984) Applied statistics: a handbook of techniques. New York: Springer.

Schnapp BJ, Vale RD, Sheetz MP, Reese TS (1985) The structure of cytoplasmic filaments involved in organelle transport in the squid giant axon. Cell 40:455-462.

Schwartz ML, Shneidman PS, Bruce J, Schlaepfer WW (1990) Axonal dependency of the postnatal upregulation in neurofilament expression. J Neurosci Res 27:193-201.

Shaw G, Weber K (1982) Differential expression of neurofilament triplet proteins in brain development. Nature 298:277-279.

Shea TB, Beermann ML (1994) Respective roles of neurofilaments, microtubules, MAP1B and tau in neurite outgrowth and stabilization. Mol Biol Cell 5:863-875.

Smith CL (1994) The initiation of neurite outgrowth by sympathetic 
neurons grown in vitro does not depend on assembly of microtubules. J Cell Biol 127:1407-1418.

Szaro BG, Tompkins R (1987) Effect of tetraploidy on dendritic branching in neurons and glial cells of the frog, Xenopus laevis. $\mathrm{J}$ Comp Neurol 258:304-316.

Szaro BG, Gainer H (1988) Identities, antigenic determinants, and topographic distributions of neurofilament proteins in the nervous systems of adult frogs and tadpoles of Xenopus laevis. J Comp Neurol 273:344-358

Szaro BG, Lee VM-Y, Gainer H (1989) Spatial and temporal expression of phosphorylated and non-phosphorylated forms of neurofilament proteins in the developing nervous system of Xenopus laevis. Dev Brain Res 48:87-103.

Szaro BG, Whitnall MH, Gainer H (1990) Phosphorylation-dependent epitopes on neurofilament proteins and neurofilament densities differ in axons in the corticospinal and primary sensory dorsal column tracts in the rat spinal cord. I Comp Neurol 302:220-235.

Szaro BG, Grant P, Lee VM-Y, Gainer H (1991) Inhibition of axonal development after injection of neurofilament antibodies into a Xenopus laevis embryo. J Comp Neurol 308:576-585.

Tabti N, Poo M-M (1991) Culturing spinal neurons and muscle cells from Xenopus embryos. In: Culturing nerve cells (Banker G, Goslin $\mathrm{K}$, eds), pp 137-154. Cambridge, MA: MIT Press.

Takeda S, Okabe S, Funakushi T, Hirokawa N (1994) Differential dynamics of neurofilament-H protein and neurofilament-L protein in neurons. J Cell Biol 127:173-185.

Tetzlaff W, Bisby MA (1989) Neurofilament elongation into regenerating facial nerve axons. Neuroscience 29:659-666.
Tompkins R (1977) Grafting analysis of the periodic albino mutant of Xenopus laevis. Proc Natl Acad Sci USA 76:4350-4354.

Torpey N, Wylie CC, Heasman J (1992) Function of maternal cytokeratin in Xenopus development. Nature 357:413-415.

Troy CM, Brown K, Greene LA, Shelanski ML (1990) Regulation of peripherin and neurofilament expression in regenerating rat motor neurons. Brain Res 529:232-238.

Vize PD, Hemmati-Brivanlou A, Harland RM, Melton DA (1991) Xenopus laevis: practical uses in cell and molecular biology, assays for gene function in developing Xenopus embryos. Methods Cell Biol 36:368-388

Weinstein DE, Shelanski ML, Liem RKH (1991) Suppression by antisense mRNA demonstrates a requirement for the glial fibrillary acidic protein in the formation of stable astrocytic processes in response to neurons. J Cell Biol 112:1205-1213.

Xu Z, Cork LC, Griffin JW, Cleveland DW (1993) Involvement of neurofilaments in motor neuron disease. J Cell Sci Suppl 17:101108

Yamasaki H, Itakura C, Mizutani M (1991) Hereditary hypotrophic axonopathy with neurofilament deficiency in a mutant strain of the Japanese quail. Acta Neuropathol (Berl) 82:427-434.

Zhao Y, Szaro BG (1994) The return of phosphorylated and nonphosphorylated epitopes of neurofilament proteins to the regenerating optic nerve of Xenopus laevis. J Comp Neurol 343:158-172.

Zhao Y, Szaro BG (1995) The optic tract and tectal ablation influence the composition of neurofilantents in regenerating optic axons of Xenopus laevis. J Neurosci 15:4629-4640. 